\title{
Annexin V in children with idiopathic nephrotic syndrome treated with cyclosporine A
}

\author{
Anna Jakubowska ${ }^{A-D}$, Katarzyna Kiliś-Pstrusińska ${ }^{A, C-F}$ \\ Department and Clinic of Pediatric Nephrology, Wroclaw Medical University, Poland \\ A - research concept and design; $B$ - collection and/or assembly of data; $C$ - data analysis and interpretation; \\ $D$ - writing the article; $E$ - critical revision of the article; $F$ - final approval of the article
}

Address for correspondence

Anna Jakubowska

E-mail:an.jakubow@gmail.com

Funding sources

None declared

Conflict of interest

None declared

Received on March 13, 2020

Reviewed on March 19, 2020

Accepted on April 30, 2020

Published online on May 28, 2020
Cite as

Jakubowska A, Kiliś-Pstrusińska K. Annexin V in children with

idiopathic nephrotic syndrome treated with cyclosporine $A$.

Adv Clin Exp Med. 2020;29(5):603-609.

doi:10.17219/acem/121519

DOI

10.17219/acem/121519

\section{Copyright}

Copyright by Author(s)

This is an article distributed under the terms of the

Creative Commons Attribution 3.0 Unported (CC BY 3.0)

(https://creativecommons.org/licenses/by/3.0/)

\section{Abstract}

Background. Treatment with cyclosporine A (CSA), a calcineurin inhibitor, is effective in children with difficult idiopathic nephrotic syndrome (INS). Prolonged CSA treatment can result in several adverse effects, the most significant being nephrotoxicity (CSAN). The plasma and urine levels of the proteins annexin V (AnV) and uromodulin (UM) were investigated in order to assess their usefulness as indicators of early-stage CSAN. Uromodulin is considered a distal tubular damage marker. Annnexin $V$ is present in the distal tubules.

Objectives. To measure AnV in children with INS receiving CSA treatment and to assess the usefulness of this biomarker for monitoring CSAN and as an indicator of changes in the distal tubules of the nephron.

Material and methods. The prospective study included 30 patients with INS and 22 controls. Plasma and urinary AnV levels were measured 3 times: before C $S A$ treatment, and after 6 and 12 months of therapy. The AnV levels were compared to those of UM.

Results. The urinary AnV and UM levels were significantly higher in the INS patients before CsA therapy in comparison to the reference group. A progressive increase of urinary AnV was observed after 6 and 12 months of therapy. Urinary UM only increased after 6 months. No significant correlations were found between plasma and urinary concentrations of the proteins studied.

Conclusions. The increased urinary excretion of AnV in children with INS receiving CsA treatment may suggest its usefulness as an early marker of subclinical CSAN. Annexin V seems to be a more sensitive indicator of tubular damage in the course of CSA therapy than UM, though large, multicenter studies are needed.

Key words: children, idiopathic nephrotic syndrome, cyclosporine nephrotoxicity, urine biomarkers 


\section{Introduction}

Idiopathic nephrotic syndrome (INS) is the most common form of primary glomerulopathy in children. Although treating INS with glucocorticosteroids leads to remission in approx. $80 \%$ of children with INS, this disease is marked by a tendency towards relapses and steroid dependence. Moreover, primary corticosteroid resistance can reach as high as $45 \%$, and a high risk of developing end-stage kidney failure has been noted (30-40\% of children, over 10 years of observation). ${ }^{1-4}$ In cases with a history of nephrotic syndrome and frequent relapses, steroid-dependent nephrotic syndrome (SDNS) or steroid-resistant nephrotic syndrome (SRNS), alternative treatments are employed, including the use of cyclosporine A (CsA).

It is estimated that CsA therapy leads to remission in $80-100 \%$ of cases of SDNS and in $30 \%$ of cases of SRNS. However, the length of CsA treatment is still controversial. Short-term therapies are associated with frequent relapses after the treatment ends, while the administration of drugs at low dosages for 18 months does not provide satisfactory results. ${ }^{5}$ Fears of administering CsA long-term mainly stem from its nephrotoxicity (CsAN).

The early clinical and laboratory indicators of cyclosporine toxicity have not yet been clearly determined. Due to individuals' varying sensitivity to the toxic effects of the drug - independent of the dosage - monitoring CsA concentration in the serum does not guarantee the safety of this therapy. An increase in the serum creatinine concentration and a decrease in glomerular filtration rate (GFR) may not be observed until advanced, irreversible changes have taken place in the kidney. Kidney biopsy and histological evaluation of kidney tissue allow for a reliable assessment of the extent of kidney damage, though this is an invasive examination - a fact which prevents the use of biopsy for continuous monitoring. Therefore, markers of early kidney damage are sought after, as they would help to improve this therapy. One such marker may be annexin $\mathrm{V}(\mathrm{AnV})$, which belongs to the family of annexins, the cytoplasmic calcium-binding proteins. ${ }^{6,7}$

Annexin V, with a molecular weight of $32-35 \mathrm{kDa}$, occurs in large amounts in the cells of the distal tubules and the glomeruli epithelium. ${ }^{8}$ It is widely used in many fields of medicine as a marker of apoptosis. It has been helpful in explaining many processes which occur in the kidneys, including acute kidney injury and diabetic nephropathy. ${ }^{9,10}$ Moreover, its usefulness as a biochemical marker of atherosclerosis has been assessed in patients with chronic kidney disease (CKD) ${ }^{11}$ and AnV has also been measured in studies on the causes behind impaired immunity in CKD patients. ${ }^{12}$

The aim of this study was to assess AnV concentrations in the plasma and urine of children with INS, depending on the disease history (steroid dependence or steroid resistance) and treatment (steroids or CsA), and to determine the usefulness of the abovementioned markers for monitoring CsAN, determining the prognosis of the disease course, and indicating changes in the distal tubules of the nephron. Values of AnV concentration have been compared to concentrations of uromodulin (UM) as another marker of distal tubule damage.

\section{Material and methods}

The study involved 52 children: 30 children with INS at the age of $9.08 \pm 3.99$ years and 22 children with primary mono-symptomatic nocturnal enuresis at the age of $10.50 \pm 3.39$ years (reference group). The INS diagnosis was based on the criteria of the International Study of Kidney Disease in Children. ${ }^{13}$ Initially, all patients with INS were treated using glucocorticosteroids (prednisone, pulses with methylprednisolone). In accordance with the criteria of the non-profit organization Kidney Disease Improving Global Outcomes from 2012, 22 patients were diagnosed with SDNS and 8 patients with SRNS. The average duration of the disease before the introduction of CsA treatment in the entire nephrotic syndrome group was $4.55 \pm 3.41$ years, while it was $5.99 \pm 2.81$ years in the SDNS group and $0.56 \pm 0.36$ years in the SRNS group. Twentytwo children were subjected to kidney biopsy before CsA therapy was initiated. Histopathological examination revealed changes which are typical of minimal change disease in 14 children, mesangial proliferation in 5 patients and focal segmental glomerulosclerosis in 1 patient. In 2 cases, kidney biopsy proved to be non-diagnostic. A biopsy was not performed in 6 patients because the typical clinical course of the disease was enough to diagnose INS. In 2 cases, the parents did not consent to the procedure.

\section{Methodology of the study}

A prospective study was conducted. The observation time of the INS patients was 12 months. In all children with INS, blood and urine were collected before CsA was administered, and then again after 6 and 12 months of the therapy. The abovementioned time points were labelled I, II and III, respectively. In children from the reference group, blood and urine samples were collected in the morning during other routinely performed examinations, and the measurements were performed once.

In all patients, fasting blood samples were drawn from the ulnar vein. Plasma samples were obtained after centrifugation and transferred to separate test tubes to be stored at $-80^{\circ} \mathrm{C}$ prior to the assay. Urine samples were collected from the first morning portion of the urine, on the day of blood collection. After centrifugation at 3,000 rpm for $15 \mathrm{~min}$, the precipitate was removed and the supernatant was frozen and stored at $-80^{\circ}$ prior to biomarker measurement.

In each patient, the concentrations of AnV and UM were measured in plasma and urine with the use of the enzymelinked immunosorbent assay (ELISA) method (eBioscience BMS252/BMS252TEN; Thermo Fisher Scientific, Waltham, 
USA). The ratio of AnV and UM to creatinine was assessed. In serum, the concentrations of urea, creatinine, uric acid, total protein, albumin, and total cholesterol were assessed; in urine, the concentrations of creatinine and protein were determined using standard laboratory methods. The GFR was estimated based on Schwartz's equation. ${ }^{14}$

The study was approved by the Ethical Committee of Wroclaw Medical University, Poland (approval No. 169/2008). The parents of all subjects were fully informed about the study, and written consent forms were obtained.

\section{Statistical analysis}

The results are presented as mean value \pm standard deviation (SD) or median value and quartile range. Differences with a significance level of $\mathrm{p}<0.05$ were considered to be statistically significant.

The normality of data distribution was verified using the D'Agostino-Pearson test. Depending on the normality of the data distribution and the homogeneity of the variance, the analysis of differences between 2 variables was conducted using Student's t-test (data with normal distribution), the Welch test (normal data without variance homogeneity) or the Mann-Whitney U test (data which does not meet the assumptions regarding normality of distribution). The significance of differences between the variables at specific time points was analyzed using a paired analysis of variance (ANOVA) test with Greenhouse-Geisser estimation or the Friedman test. Additionally, the post hoc analysis was conducted using multiple iterations of Student's t-test or the Wilcoxon test (for ANOVA and Friedman, respectively) for paired data. In both cases, Bonferroni correction was applied.

\section{Results}

During the 12-month observation, no disorders of the excretory function of the kidneys were observed in any of the patients with INS. Serum urea, creatinine and uric acid concentration did not differ significantly in different time points, and no differences were noted in regard to GFR (Table 1). Blood CsA concentrations remained within the therapeutic range $(65.2 \pm 31.4 \mathrm{ng} / \mathrm{mL})$.

In the group of INS patients, before the introduction of CsA, the concentrations of AnV and UM were significantly higher than in the reference group (Table 2). Plasma AnV concentrations rose gradually during the observation period, and their values significantly differed between

Table 1. Plasma creatinine concentrations and GFR in patients with INS at 3 time points: before CsA (I) treatment, and after 6 (II) and 12 (III) months of CSA therapy

\begin{tabular}{|c|c|c|c|c|}
\hline \multirow[b]{3}{*}{ Parameter } & \multicolumn{3}{|c|}{ Time point } & \multirow[b]{3}{*}{$p$-value ${ }^{a}$} \\
\hline & $\bar{I}$ & II & III & \\
\hline & $\begin{array}{c}\text { mean } \pm S D \\
\text { median } \\
(1-3 \text { quartile })\end{array}$ & $\begin{array}{c}\text { mean } \pm \mathrm{SD} \\
\text { median } \\
\text { (1-3 quartile) }\end{array}$ & $\begin{array}{c}\text { mean } \pm \text { SD } \\
\text { median } \\
\text { (1-3 quartile) }\end{array}$ & \\
\hline Creatinine in plasma [mg/dL] & $\begin{array}{c}0.50 \pm 0.14 \\
0.48(0.41-0.59)\end{array}$ & $\begin{array}{c}0.47 \pm 0.13 \\
0.44(0.40-0.53)\end{array}$ & $\begin{array}{c}0.54 \pm 0.15 \\
0.49(0.45-0.62)\end{array}$ & 0.11 \\
\hline $\mathrm{GFR}\left[\mathrm{mL} / \mathrm{min} / 1.73 \mathrm{~m}^{2}\right]$ & $\begin{array}{c}147 \pm 34.7 \\
145(127-163)\end{array}$ & $\begin{array}{c}142 \pm 47.3 \\
150(129.3-177)\end{array}$ & $\begin{array}{c}137.5 \pm 33.6 \\
151(102-160)\end{array}$ & 0.74 \\
\hline
\end{tabular}

${ }^{a}$ comparison of values at 3 time points; p-value - level of significance; highlighted $\mathrm{p}<0.05$; GFR - glomerular filtration rate; INS - idiopathic nephrotic syndrome; CsA - cyclosporine A.

Table 2. Comparison of AnV and UM concentrations in plasma $(\mathrm{p})$ and urine $(\mathrm{u})$ between group of children with INS before CsA treatment and the reference group

\begin{tabular}{|c|c|c|c|}
\hline Parameter & $\begin{array}{c}\text { Children with INS }(\mathrm{n}=30) \\
\text { mean } \pm \text { SD } \\
\text { median ( } 1-3 \text { quartile })\end{array}$ & $\begin{array}{c}\text { Reference group }(\mathrm{n}=22) \\
\text { mean } \pm \mathrm{SD} \\
\text { median ( } 1-3 \text { quartile) }\end{array}$ & $\mathrm{p}$-value \\
\hline $\mathrm{p} A n V[n g / m L]$ & $\begin{array}{c}30.81 \pm 1.62 \\
31.08(29.38-32.32)\end{array}$ & $\begin{array}{c}18.10 \pm 1.04 \\
18.04(17.23-19.11)\end{array}$ & 0.0001 \\
\hline $\mathrm{p} \cup M[\mathrm{ng} / \mathrm{mL}]$ & $\begin{array}{c}11.28 \pm 0.60 \\
11.40(10.80-11.81)\end{array}$ & $\begin{array}{c}6.21 \pm 0.94 \\
6.38(5.32-7.07)\end{array}$ & 0.0001 \\
\hline $\begin{array}{l}\text { u AnV/u creatinine } \\
\text { [ng/mg] }\end{array}$ & $\begin{array}{c}15.28 \pm 2.31 \\
14.61(13.58-16.91)\end{array}$ & $\begin{array}{c}5.37 \pm 0.28 \\
5.36(5.20-5.48)\end{array}$ & 0.0001 \\
\hline $\begin{array}{l}\text { u UM/u creatinine } \\
\text { [ng/mg] }\end{array}$ & $\begin{array}{c}4.93 \pm 0.88 \\
4.80(4.15-5.45)\end{array}$ & $\begin{array}{c}1.93 \pm 0.22 \\
1.92(1.82-2.04)\end{array}$ & 0.0001 \\
\hline u total protein/u creatinine $[\mathrm{mg} / \mathrm{mg}]$ & $\begin{array}{c}5.14 \pm 9.41 \\
0.85(0.00-5.81)\end{array}$ & $\begin{array}{c}0.06 \pm 0.02 \\
0.00(0.00-0.00)\end{array}$ & 0.0005 \\
\hline
\end{tabular}

p - plasma; u - urine; $p$ - level of significance; highlighted p < 0.05. SD - standard deviation; INS - idiopathic nephrotic syndrome; UM - uromodulin; AnV - annexin $V_{;}$CsA - cyclosporine A. 
Table 3. Concentration values of studied variables in plasma ( $\mathrm{p}$ ) and urine ( $\mathrm{u}$ ) of the patients suffering from INS in 3 time points: before CsA treatment (I), and after 6 (II) and 12 (III) months of therapy

\begin{tabular}{|c|c|c|c|c|}
\hline \multirow[b]{3}{*}{ Parameter } & \multicolumn{3}{|c|}{ Time point } & \multirow[b]{3}{*}{$p$-value ${ }^{a}$} \\
\hline & I & $\|$ & III & \\
\hline & $\begin{array}{c}\text { mean } \pm \text { SD } \\
\text { median } \\
\text { (1-3 quartile) }\end{array}$ & $\begin{array}{c}\text { mean } \pm S D \\
\text { median } \\
\text { (1-3 quartile) }\end{array}$ & $\begin{array}{c}\text { mean } \pm \text { SD } \\
\text { median } \\
\text { (1-3 quartile) }\end{array}$ & \\
\hline $\mathrm{p} A n V[n g / m L]$ & $\begin{array}{c}30.81 \pm 1.62 \\
31.08(29.38-32.32)\end{array}$ & $\begin{array}{c}38.22 \pm 2.46 \\
38.5(37.84-39.09)\end{array}$ & $\begin{array}{c}39.35 \pm 1.23 \\
39.33(38.63-39.8)\end{array}$ & $<0.0001$ \\
\hline$p \cup M[n g / m L]$ & $\begin{array}{c}11.28 \pm 0.60 \\
11.40(10.80-11.81)\end{array}$ & $\begin{array}{c}13.95 \pm 0.16 \\
13.98(13.9-14.06)\end{array}$ & $\begin{array}{c}13.95 \pm 0.21 \\
14.0(13.92-14.09)\end{array}$ & $\begin{array}{c}<0.0001 \\
*\end{array}$ \\
\hline u AnV/u creatinine [ng/mg] & $\begin{array}{c}15.28 \pm 2.31 \\
14.61 \\
(13.58-16.91)\end{array}$ & $\begin{array}{c}16.69 \pm 1.68 \\
16.05 \\
(15.55-7.68)\end{array}$ & $\begin{array}{c}17.09 \pm 1.56 \\
16.77 \\
(15.79-18.22)\end{array}$ & $<0.0001$ \\
\hline u UM/u creatinine [ng/mg] & $\begin{array}{c}4.93 \pm 0.88 \\
4.80 \\
(4.15-5.45)\end{array}$ & $\begin{array}{c}6.63 \pm 0.85 \\
6.34 \\
(5.92-7.34)\end{array}$ & $\begin{array}{c}6.41 \pm 0.93 \\
6.33 \\
(5.75-7.09)\end{array}$ & $\begin{array}{c}<0.0001 \\
*\end{array}$ \\
\hline
\end{tabular}

a comparison of values at 3 time points; p-value - level of significance; highlighted p < 0.05; *I vs II and I vs III; SD - standard deviation; UM - uromodulin; AnV - annexin V.

all time points in the study. Plasma UM concentrations in the group of children with INS before CsA were significantly lower than in subsequent time points of the therapy. No statistically significant difference in the concentration of this protein was noted after 6 or 12 months of treatment (Table 3). Urine AnV concentration in the INS group was significantly higher after 6 months of CsA treatment, compared to the baseline values. A further increase in the concentration of this protein was observed after 12 months of therapy ( $<$ 0.0001; Fig. 1). Urine UM concentrations after 6 and 12 months of therapy were significantly higher than the values from before the treatment, but the differences of urine UM after 6 and 12 months of administering the drug were not statistically significant (Fig. 2).

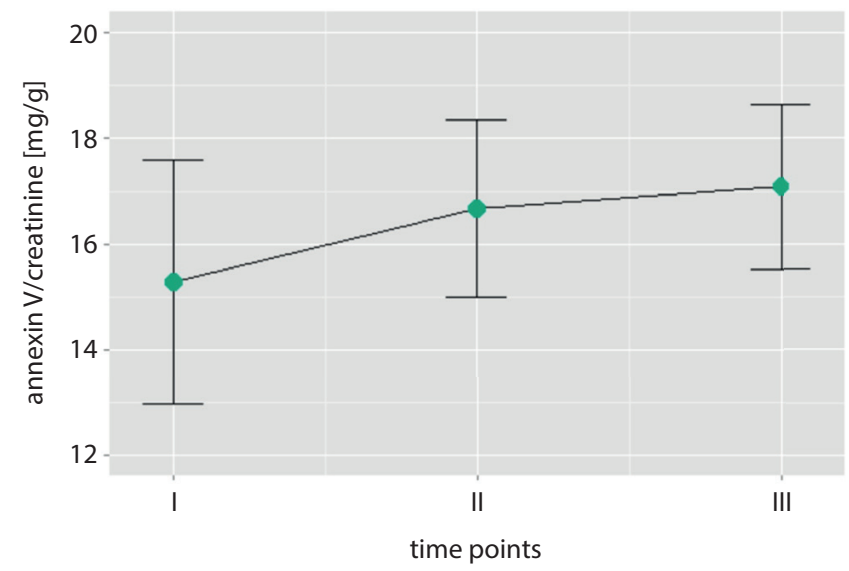

Fig. 1. Comparison of urine AnV concentrations in INS patients at 3 time points: before CsA treatment (I) and after 6 (II) and 12 (III) months of therapy

\section{Correlations between the studied variables in the group of INS patients before the start of CsA treatment (time point I)}

Before the CsA therapy, there were no statistically significant correlations noted between plasma (p) AnV and UM concentrations and the concentrations of these proteins in the urine $(\mathrm{u}): \mathrm{pAnV}$ vs $\mathrm{uAnV}-\mathrm{r}=-0.12, \mathrm{p}=0.52$; and $\mathrm{pUM}$ vs $\mathrm{uUM}-\mathrm{r}=0.02, \mathrm{p}=0.93$. Likewise, there were no statistically significant correlations found between the concentrations of AnV and UM in the plasma $(\mathrm{r}=-0.20, \mathrm{p}=0.29)$, while on the other hand there was significant correlation noted between studied proteins in the urine (uAnV vs uUM r = 0.67, p < 0.0001; Fig. 3). No significant correlations were found concerning urine $\mathrm{AnV}$ and UM in regard to the urine protein.

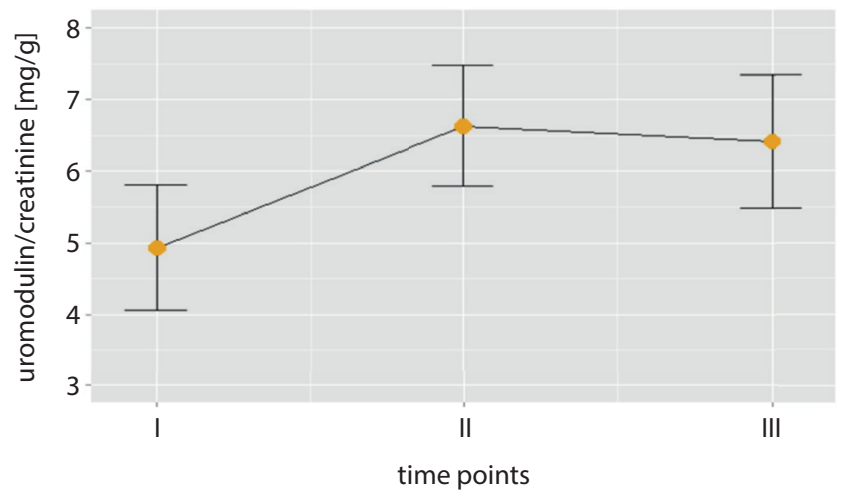

Fig. 2. Comparison of urine UM concentrations in INS patients at 3 time points: before CsA treatment (I) and after 6 (II) and 12 (III) months of therapy 


\section{Correlations between the studied variables in the INS patients after 6 and 12 months of CsA treatment (time points II and III)}

After 6 and 12 months of CsA treatment, there were no statistically significant correlations between the concentrations of the variables of interest in the plasma and urine, or between the concentrations of AnV and UM in the plasma. Statistically significant correlations were noted between the concentrations of AnV and UM in the urine ( $r=0.68$ and $r=0.64$ after 6 and 12 months, respectively; $\mathrm{p}<0.0001$; Fig. 3).

No correlation was found between urine AnV and UM concentrations and blood CsA concentration, after either 6 or 12 months of the treatment. At the selected time points, no significant correlations were found between the urine AnV and UM and proteinuria.

The AnV concentrations measured in the urine of patients with INS before CsA treatment and after 6 and 12 months of therapy did not correlate with the GFRs, assessed at 3 time points. There was also no correlation between serum CsA concentration and eGFR (Table 4).

No significant differences were noted between the SDNS patients and the SRNS patients in terms of the selected parameters in the plasma and urine.

\section{Discussion}

Our study showed significantly higher concentrations of AnV in the plasma and urine of children with INS in comparison with the healthy children, which suggests the involvement of this protein in the pathomechanism of the disease. Similarly, other authors have found higher concentrations of AnV in the urine of patients suffering from primary glomerulopathies, and in patients with other diseases which affect the kidneys. ${ }^{15}$

The pathomechanism of the increased AnV concentrations in patients with kidney diseases is not clear. The protein occurs in the kidneys primarily in the distal tubules and epithelial cells of Bowman's capsule. ${ }^{8,16}$ According to Matsuda et al., the increase of its concentration in the urine may indicate damage to those parts of the nephron, just as, e.g., lysosomal enzymes (NAG) or small-molecule proteins, such as $\alpha_{1}$-microglobulin and $\beta_{2}$-microglobulin, are markers of disorders in the proximal tubules. ${ }^{16}$ The experimental glomerulonephritis in rats showed high concentrations of AnV in the urine, concurrent with increased secretion of B NAG isoenzyme. ${ }^{16}$ Annexin $\mathrm{V}$ was found on the luminal surface of the cell membranes of the distal tubules and in their lumen, and outflow of this protein from the tubule cells was observed.

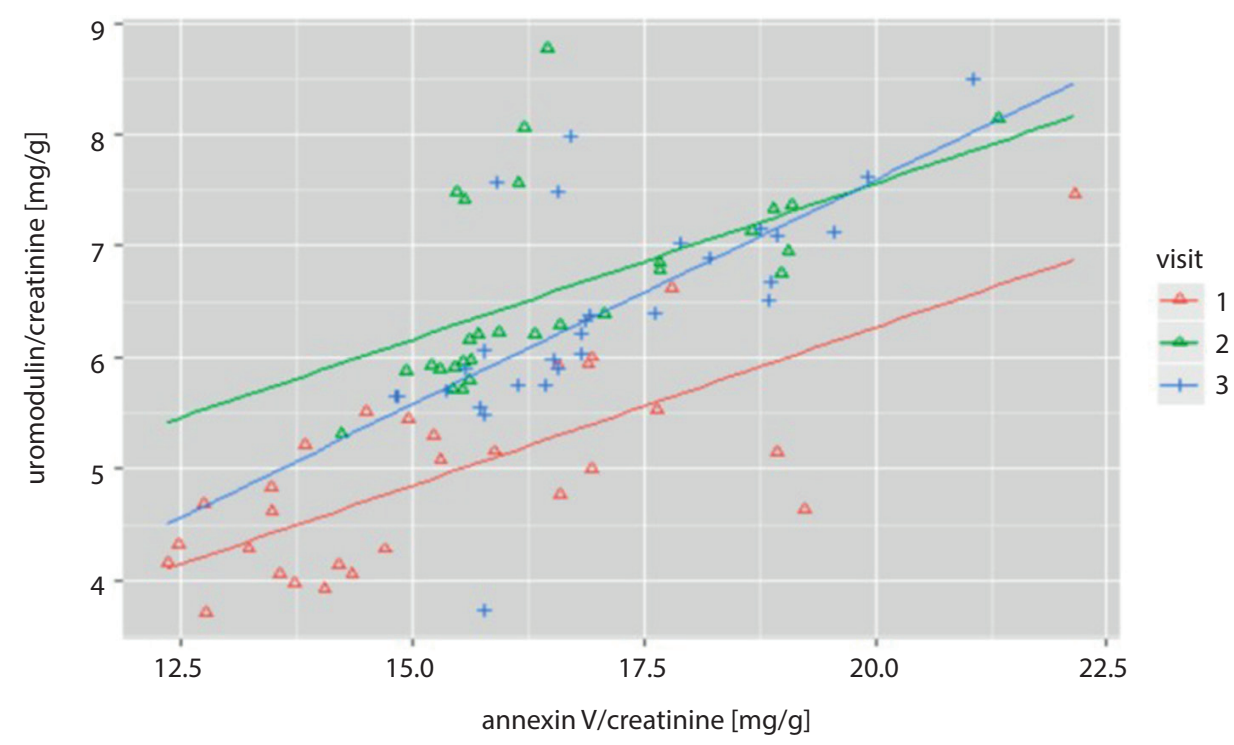

Fig. 3. Correlations between urinary concentrations of AnV and UM in INS patients at 3 time points

Table 4. Correlations between concentrations of AnV, CsA and GFR of the patients suffering from INS in 3 time points: before CsA treatment (I), and after 6 (II) and 12 (III) months of therapy

\begin{tabular}{|c|c|c|c|}
\hline Parameter & $\mathrm{GFR} I\left[\mathrm{~mL} / \mathrm{min} / 1.73 \mathrm{~m}^{2}\right]$ & GFR II [mL/min/1.73 m²] & GFR III $\left[\mathrm{mL} / \mathrm{min} / 1.73 \mathrm{~m}^{2}\right]$ \\
\hline u AnV/u creatinine $[\mathrm{ng} / \mathrm{mg}]$ & $\begin{array}{l}r=0.06 \\
p=0.77\end{array}$ & $\begin{array}{l}r=-0.3 \\
p=0.26\end{array}$ & $\begin{array}{c}r=-0.37 \\
p=0.18\end{array}$ \\
\hline $\mathrm{CsA}[\mathrm{ng} / \mathrm{mL}]$ & - & $\begin{array}{c}r=-0.28 \\
p=0.36\end{array}$ & $\begin{array}{c}r=-0.15 \\
p=0.59\end{array}$ \\
\hline
\end{tabular}

GFR - glomerular filtration rate; AnV - annexin V; CsA - cyclosporine A; INS - idiopathic nephrotic syndrome; u - urine; $\mathrm{P}$ - level of significance; highlighted $p<0.05$. 
Moreover, a relationship was found between the concentration of AnV in the urine and the degree of kidney tissue damage.

The previously cited work of Matsuda et al. ${ }^{15}$ reported AnV concentrations in the urine of patients with nephrotic syndrome, lupus nephritis, IgA nephropathy, and CKD, as well as in healthy people. Significantly higher concentrations of $\mathrm{AnV}$ were noted in the first 2 groups of patients compared to the others, and the highest levels were found in the patients with nephrotic syndrome. This is consistent with our observations of children with INS. Similar results were presented by Simsek et al. in a study on children with nephrotic syndrome..$^{18}$ Their research also confirms our observations regarding plasma AnV concentration (higher in sick children than in healthy children) and the lack of correlation between concentrations of AnV in the plasma and urine.

The origin of AnV excreted with urine has not yet been determined. The lack of a correlation between concentrations of AnV in the plasma and the urine suggests that the increased urine AnV concentration in INS cannot be regarded as a consequence of increased excretion by the basal membrane of the glomeruli. This is also supported by the fact that we did not find a correlation between AnV excretion in the urine and proteinuria. This is consistent with the study by Simsek et al., ${ }^{18}$ though it differs from the observations of Matsuda et al. regarding adults..$^{15}$ These authors have shown a positive correlation with proteinuria (defined as the concentration of protein in urine) and suggested that a high concentration of AnV in the urine may be an indicator of acute kidney damage, resulting in proteinuria. This difference of observations may be due, as other authors have pointed out, ${ }^{18}$ to agedependent kidney function and metabolism. It may also be a consequence of the methods used and the method of assessing the amount of protein in the urine. In our study, the protein to creatinine concentration ratio has been calculated in urine, which increases the reliability of results.

The reason for the increased plasma AnV concentrations in children suffering from INS that we observed is unclear. It is known that the basic pathophysiological role of this protein is associated with cell apoptosis, and that higher indicators of apoptosis of circulating lymphocytes have been reported in children with nephrotic syndrome. ${ }^{19}$ The protein also occurs in leukocytes and platelets, and disorders of these cells are one element of the syndrome. ${ }^{15,20}$ The wide variance of AnV concentration in the plasma of healthy people which has been observed by other authors additionally supports the idea that there are many determinants of these markers. ${ }^{18}$ Therefore, AnV concentration in the urine may better reflect kidney changes than concentrations in the plasma, especially since some researchers did not observe any differences in the level of this protein between sick and healthy people at all. ${ }^{21}$

In recent years, more and more emphasis has been placed on changes in the distal tubules in the course of nephrotic syndrome. ${ }^{22,23}$ For example, Tudpor et al., ${ }^{24}$ in an animal model of nephrotic proteinuria, demonstrated its negative impact on the distal tubules by changes in TRVP5, leading to disorders of the intercellular transport of $\mathrm{Ca}^{+2}$. In these processes, which involve the protein kinase $\mathrm{C}$, the $\mathrm{AnV}$ may play a regulating role. ${ }^{25}$

We did not find differences in urine AnV concentrations between patients suffering from SRNS and SDNS. On the other hand, Simsek et al. demonstrated higher AnV concentrations in the urine of patients suffering from SRNS than in patients with SSNS. ${ }^{18}$ It is difficult to compare these results to those of our study. Our study involves children with SDNS and SRNS, in which the vast majority of kidney biopsies found changes typical of minimal change disease and mesangial proliferation. However, most of the kidney biopsies of children with SRNS studied by Turkish authors displayed focal segmental glomerulosclerosis (FSGS). ${ }^{18}$ It is known that in the course of nephrotic syndrome in children, there may be a noticeable evolution of morphological images of the kidney biopsies; therefore, we cannot exclude the different degrees of advancement of glomerulopathy in the study groups, hence the different observations. On the basis of their research, Simsek et al. suggested that AnV in the urine may be an indicator of steroid resistance and that it may be significant in predicting the disease course. ${ }^{18}$ The results of our own study, however, suggest that the measuring $\mathrm{AnV}$ in the urine as a predictor of the response to steroid treatment in children with INS requires further research on larger samples. In the study by Simsek et al., the analysis covered the data from 23 children with SSNS and 22 with SRNS, while in our study, the group of children with SRNS consisted of only 8 children and the majority of the study group (22 patients) were children with SDNS. ${ }^{18}$

In this study, we did not find a statistically significant difference in the concentrations of AnV and UM in the urine among the children with SRNS and SDNS, either before the start of CsA therapy or during the treatment. This finding suggests a lack of association between possible CsAN and resistance to steroid treatment. The views of Sinha et al. on this matter are different, though, because they believe that starting resistance to steroids is one of the risk factors of CsAN, while the others include duration of the disease, massive proteinuria and hypertension during therapy. ${ }^{26}$ These differing observations may result from the different characteristics of the patients with SRNS: none of them showed hypertension or severe proteinuria. It should be also noted that in other studies concerning CsAN, the response to steroid treatment was not described as a risk factor for adverse effects of the drug.

In our study, we attempted to assess the usefulness of AnV as a marker in children suffering from INS and being treated with CsA. We reported an increasing value of AnV concentration in the urine of sick patients in subsequent months of CsA therapy. While taking into account the fact that the children were in nephrotic syndrome 
remission, the observed increase in the concentration of this protein, assessed after 6 months and 12 months of treatment, may indicate the ongoing processes that damage the cells of distal tubules and may be the result of the nephrotoxicity effect of the drug. In this study, we related the AnV concentrations to the concentrations of UM, a glycoprotein with a molecular weight of $80-90 \mathrm{kDa}$ which is produced almost exclusively by the cells of the distal tubules and the ascending limb of the loop of Henle. ${ }^{27}$ We found higher concentrations of UM in the urine of sick children before the introduction of CsA therapy than in healthy children, which may confirm that the distal tubules are damaged in the course of the underlying disease. The treatment with CsA resulted in further increases in this protein level after 6 months of treatment. This finding suggests that despite remission of the disease, there is a progression of changes in the distal tubules due to the side effect of the drug. However, the values of UM concentration in the urine after an additional 6 months were stable, unlike in the case of AnV. Perhaps AnV is not only an early, but also a sensitive marker of CsAN. Its usefulness as a marker in children with INS and undergoing treatment with calcineurin inhibitors requires further studies. It would be interesting to perform a study concerning AnV in children with different histopathological types of nephrotic syndrome. This is one of the limitations of our study. It should also take into account the issue of response to steroids (resistance/ dependency) as a risk factor for nephrotoxicity of the drug.

\section{Conclusions}

An increase in urine AnV concentration can be found in children with INS and being treated with CsA, which suggests that AnV may be useful as a marker for monitoring the therapy. Increased excretion of the proteins of the distal tubules in the urine of patients suffering from INS and undergoing CsA treatment, in the absence of other indicators of CsAN, indicates that as early as after 6 months of pharmacotherapy, functional impairment of the kidney tubules may occur. Annexin V seems to be a more sensitive indicator of changes in the distal tubules in cyclosporine therapy than UM. The usefulness of AnV as an indicator in the urine of children suffering from INS and treated with calcineurin inhibitors requires further studies.

\section{ORCID iDs}

Anna Jakubowska (D) https://orcid.org/0000-0002-7732-3487 Katarzyna Kiliś-Pstrusińska (D) https://orcid.org/0000-0001-7352-6992

\section{References}

1. Zagury A, Oliveira AL, Montalvão JA, et al. Steroid-resistant idiopathic nephrotic syndrome in children: Long-term follow-up and risk factors for end-stage renal disease. J Bras Nefrol. 2013;35(3):191-199.

2. Mekahli D, Liutkus A, Ranchin B, et al. Long-term outcome of idiopathic steroid-resistant nephrotic syndrome: A multicenter study. Pediatr Nephrol. 2009;24(8):1525-1532.
3. Cattran DC, Rao P. Long-term outcome in children and adults with classic focal segmental glomerulosclerosis. Am J Kidney Dis. 1998; 32(1):72-79.

4. Kim JS, Bellew CA, Silverstein DM, Aviles DH, Boineau FG, Vehaskari VM. High incidence of initial and late steroid resistance in childhood nephrotic syndrome. Kidney Int. 2005;68(3):1275-1281.

5. Ishikura K, Ikeda M, Hattori S, et al. Effective and safe treatment with cyclosporine in nephrotic children: A prospective, randomized multicenter trial. Kidney Int. 2005;73(10):1167-1173.

6. Gerke V, Moss SE. Annexins: From structure to function. Physiol Rev. 2002;82(2):331-371.

7. Lizarbe MA, Barrasa Jl, Olmo N, Gavilanes F, Turnay J. Annexin-phospholipid interactions: Functional implications. Int J Mol Sci. 2013;14(2): 2652-2683.

8. Marchewka Z. Low molecular weight biomarkers in the nephrotoxicity. Adv Clin Exp Med. 2006;15(6):1129-1138.

9. Wever KE, Wagener FA, Frielink C, et al. Diannexin protects against renal ischemia reperfusion injury and targets phosphatidylserines in ischemic tissue. PLoS One. 2011;6(8):e24276. doi:10.1371/journal. pone.0024276

10. Bamri-Ezzine S, Ao ZJ, Londoño I, Gingras D, Bendayan M. Apoptosis of tubular epithelial cells in glycogen nephrosis during diabetes. Lab Invest. 2003;83(7):1069-1080.

11. Emanuel VL, Mnuskina MM, Smirnov AV, et al. Annexin-5 as a biochemical marker of early vascular disorders under chronic disease of kidneys [in Russian]. Klin Lab Diagn. 2013;4:9-10.

12. Meier P, Dayer E, Blanc E, Wauters JP. Early T cell activation correlates with expression of apoptosis markers in patients with end-stage renal disease. J Am Soc Nephrol. 2002;13(1):204-212.

13. International Study of Kidney Disease in Children. Primary nephrotic syndrome in children: Clinical significance of histopathologic variants of minimal change and of diffuse mesangial hypercellularity. A Report of the International Study of Kidney Disease in Children. Kidney Int. 1981;20(6):765-771.

14. Schwartz GJ, Brion LP, Spitzer A. The use of plasma creatinine concentration for estimating glomerular filtration rate in infants, children, and adolescents. Pediatr Clin North Am. 1987;34(3):571-590.

15. Matsuda R, Kaneko N, Horikawa Y, et al. Measurement of urinary annexin $\mathrm{V}$ by ELISA and its significance as a new urinary marker of kidney disease. Clin Chim Acta. 2000;298(1-2):29-43.

16. Matsuda R, Kaneko N, Horikawa $Y$, et al. Localization of annexin $V$ in rat normal kidney and experimental glomerulonephritis. Res Exp Med (Berl). 2001;200(2):77-92.

17. Tomlinson PA. Low molecular weight proteins in children with renal disease. Pediatr Nephrol. 1992;6(6):565-571.

18. Simsek B, Buyukcelik M, Soran M, et al. Urinary annexin V in children with nephrotic syndrome: A new prognostic marker? Pediatr Nephrol. 2008;23(1):79-82.

19. Zachwieja J, Dworacki G, Bobkowski W, Dobrowolska-Zachwieja A, Zaniew M, Maciejewski J. Increased apoptosis of peripheral blood lymphocytes in children with nephrotic syndrome. Pediatr Nephrol. 2002;17(3):197-200.

20. Sinha A, Bagga A. Nephrotic syndrome. Indian J Pediatr. 2012;79(8): 1045-1055.

21. Kaneko N, Matsuda R, Hosoda S, Kajita T, Ohta Y. Measurement of plasma annexin $\mathrm{V}$ by ELISA in the early detection of acute myocardial infarction. Clin Chim Acta. 1996;251(1):65-80.

22. Chugh SS, Clement LC, Macé C. New insights into human minimal change disease: Lessons from animal models. Am J Kidney Dis. 2012; 59(2):284-292.

23. Zhang S, Audard V, Fan Q, Pawlak A, Lang P, Sahali D. Immunopathogenesis of idiopathic nephrotic syndrome. Contrib Nephrol. 2011;169:94-106.

24. Tudpor K, Laínez S, Kwakernaak AJ, et al. Urinary plasmin inhibits TRPV5 in nephrotic-range proteinuria. J Am Soc Nephrol. 2012;23(11): 1824-1834.

25. Schlaepfer DD, Jones J, Haigler HT. Inhibition of protein kinase C by annexin V. Biochemistry. 1992;31(6):1886-1891.

26. Sinha A, Sharma A, Mehta A, et al. Calcineurin inhibitor induced nephrotoxicity in steroid resistant nephrotic syndrome. Indian J Nephrol. 2013;23(1):41-46

27. Devuyst O, Dahan K, Pirson Y. Tamm-Horsfall protein or uromodulin: New ideas about an old molecule. Nephrol Dial Transplant. 2005; 20(7):1290-1294. 